\title{
Hyperuricemia and Adverse Pregnant Outcomes in Ghanaian Women: Potential Mechanism
}

\author{
Ababio GK $^{1 *}$, Adu-Bonsaffoh $\mathrm{K}^{2}$, Botchway $\mathrm{F}^{3}$, Abindau $\mathrm{E}^{4}$ and Quaye IKE \\ ${ }^{1}$ Department of Medical Biochemistry, University of Ghana SBAHS, Accra, Ghana \\ ${ }^{2}$ Department of Obstetrics and Gynecology, Korle-Bu Teaching Hospital, Accra, Ghana \\ ${ }^{3}$ Department of Child Health, Korle-Bu Teaching Hospital, Accra, Ghana \\ ${ }^{4}$ Department of Physiology, University of Ghana SBAHS, Accra, Ghana \\ ${ }^{5}$ Department of Medical Biochemistry, University of Namibia, School of Medicine, Accra, Ghana
}

\begin{abstract}
Background: Hyperuricemia has been associated with pre-eclampsia (PE) but limited data exist on the potential mechanism for the association. It is therefore imperative that data is collated for the pathogenic role of urate in PE; hence the focus.
\end{abstract}

Aim: To investigate the association between uric acid levels and pregnancy outcomes in Ghanaian women.

Methodology: The nested case control study was located at the Obstetrics and Gynecology department of the Korle-Bu Teaching Hospital (KBTH). One hundred and fourteen consented subjects were recruited after ethical clearance was obtained and structured questionnaire administered to them. Four milliliter $(4 \mathrm{ml})$ blood and five milliliter $(5 \mathrm{ml})$ urine samples were taken for biochemical analysis and urinalysis respectively. An automated chemistry analyzer was used to quantify blood chemistry. The data was captured as protected health information (PHI) and analyzed with SPSS version 18.

Results: In pre-eclampsia, patients with hyperuricemia ( $>360$ umol/L) were associated with low birth weight (1033.3 $\pm 57.7)$. Among the pregnant women with lesser weeks of gestation (<34 weeks), PE patients had their uric acid levels elevated, Apgar scores decreased and birth-weight decreased compared to $\geq 34$ weeks gestation category.

Conclusion: Increased uric acid levels could generate free radicals that might impair the endothelial system and cause adverse pregnant outcomes.

\section{Introduction}

Uric acid is a danger signaling [1] molecule generated from tissue injury, inflammatory cell death, programmed necrosis and or abnormal metabolism. In such states, uric acid activates macrophages and dendritic cells through pattern recognition receptors [2-4] or indirectly through tissue damage and homeostatic perturbations (from inflamed tissue e.g. decreased $\mathrm{pH}$ and hypoxia) resulting in the increment of cytokines and chemokines. Cytokines and chemokines sustain the inflammatory response needed to recruit secondary mediators like leucocytes or white blood cells (WBC) and neutrophils for innate immunity $[5,6]$.

A good example of a damaged tissue could possibly distort the genetic composition which is composed of sugar, pyrimidines and purines. Uric acid, a by-product of purine catabolism, is degraded by hepatic enzyme, uricase [7-17]. The normal range for urate in females is $140-360 \mu \mathrm{mol} / \mathrm{L}$. This level varies significantly in humans as a result of factors that decrease excretion or increase generation. Alcohol, low water consumption, high-purine foods consumption and poor exercise are contributing factors to hyperuricemia (high uric acid levels).

The association of hyperuricemia with hypertension has since been recognized by early investigators [7-15,18], suggesting that uric acid might play a pathogenic role in hypertension mediated by several mechanisms such as inflammation, vascular smooth muscle cell proliferation, endothelial dysfunction, activation of the renin angiotensin - aldosterone system and oxidative stress [19-21].

Other factors may also contribute to why uric acid is associated with hypertension, including alcohol abuse, lead intoxication, obesity and insulin resistance, and diuretic use $[22,23]$. Lactate has also been known to block urate secretion in the proximal tubes whereas ischemia results in increased uric acid synthesis. According to Sonne et al., [24], lactate, pyruvate and acetate are precursors of uric acid. The conversion of lactate to pyruvate is catalyzed by lactate dehydrogenase (LDH). Elevated levels of LDH indicate cellular death and leakage of the enzyme from the cell [25]. High levels of LDH have also been found to be associated with severe pre-eclampsia in a limited number of studies $[26,27]$. LDH isozymes and hyperuricemia still remain implicated in cardiovascular disorders [28].

In ischemia, hyperuricemia [29] as well as oxidant formation [30,31] occurs when ATP is degraded to adenine and xanthine. The finding that ischemia results in an increment of uric acid levels may also account for why uric acid levels increases in pre-eclampsia.

Pre-eclampsia (PE) is a pregnancy - related disease with altered vascular reactivity that leads to hypertension in mother and metabolic alteration of fetus [32]. It is a major public health concern complicating $5 \%$ to $7 \%$ of all pregnancies $[33,34]$ and causing significant maternal and perinatal morbidity and mortality. PE is therefore a multisystem [35] and multifactorial disorder with no specific identifiable etiology. Numerous methods have been used to predict the onset of PE with

*Corresponding author: Ababio GK, Department of Medical Biochemistry, University of Ghana SBAHS, Accra, Ghana, Tel: +233-302-666987-8; Fax: +233 302-663062; E-mail: esugms@yahoo.com

Received: March 22, 2016; Accepted: May 21, 2016; Published May 24, 2016

Citation: Ababio GK, Adu-Bonsaffoh K, Botchway F, Abindau E, Quaye IKE (2016) Hyperuricemia and Adverse Pregnant Outcomes in Ghanaian Women: Potential Mechanism. Biochem Anal Biochem 5: 275. doi:10.4172/2161-1009.1000275

Copyright: ( 2016 Ababio GK, et al. This is an open-access article distributed under the terms of the Creative Commons Attribution License, which permits unrestricted use, distribution, and reproduction in any medium, provided the original author and source are credited. 
varying degrees of efficiency [36-38]. These methods have used fetal/ placental and maternal markers in different stages of pregnancy in order to predict the disease. However, impaired endothelial dysfunction [39] and genetic predisposition have been cited as possible pathogenic pathways. In this study, hyperuricemia is envisaged to play a role in this pathogenic pathway. Based on the fact that uric acid is produced during tissue or vessel injury, we hypothesized that crystals of uric acid formed at sites of blood vessel injury is a danger molecule that could elicit inflammation in PE patients causing low birth-weight, hence the focus.

\section{Aim}

To investigate the mechanism and association between uric acid levels and pregnancy outcomes in Ghanaian women.

\section{Methods}

Anthropometry: A questionnaire for clinical information was obtained after informed consent and ethical review (MS-Et/M.3 P.3.2/2013 - 2014) for this nested case-control study situated at the Obstetrics and Gynecology unit, Korle-Bu teaching hospital, Accra. The sample consisted of 130 participants; fifty controls, fifty pregnant normotensives and thirty PE. Subjects that did not complete the entire study and were lost to follow up were made up of one pregnant normotensive, ten controls and 5 PE. In all, one hundred and fourteen (114) completed the study.

Body mass index: Weights and heights were obtained and computed for body mass index (BMI). At risk for overweight was defined using the international body mass index (BMI) cutoff points by the World Health Organization's (WHO) International Obesity Task Force [40].

\section{Dependent variable: Uric acid levels}

Independent variables: Body mass index (BMI), Age, blood pressure, lactate dehydrogenase, week of gestation, birth-weight, Apgar scores and full blood count (FBC).

Inclusion and exclusion criteria: Only patients diagnosed with $\mathrm{PE}$ were recruited after obtaining their consent as cases. Control subjects will include normotensive pregnant and non-pregnant women who gave informed consent were included in the study. Patients with a history of chronic hypertension, renal disease, diabetes, urinary tract infection, cardiovascular disease, multiple pregnancy, molar pregnancy, thyroid dysfunctions and infectious diseases were excluded.

Blood collection and processing: Four milliliter $(4 \mathrm{ml})$ blood was drawn from an antecubital vein by means of a plastic syringe and dispensed into EDTA (for FBC) and gel tubes taking careful precautions. Sysmex hematological auto analyzer was used to quantify
FBC whilst RANDOX auto analyzer was used for the determination of $\mathrm{LDH}$ and uric acid levels.

Urinalysis: Five milliliter spot urine was obtained to determine proteinuria and to categorize subjects into normotensives and PE.

Blood pressure measurements: Omron BP monitor was used to determine hypertensives and to group patients into cases and controls.

For the purposes of this study, PE was defined based on American College of Obstetricians and Gynecologist criteria. Accordingly, PE is defined as diastolic blood pressure of $\geq 90 \mathrm{mmHg}$ and or systolic blood pressure of $\geq 140 \mathrm{mmHg}$ with proteinuria $100 \mathrm{mg} / \mathrm{dl}$ in a random urine sample and $\geq 300 \mathrm{mg} / \mathrm{dl}$ in 24 -hr urine sample occurring after 20 weeks of gestation $[41,42]$.

\section{Data management}

As part of data management, the physical integrity of patient records, ethics, data protection were taken into consideration. Data were created on a spreadsheet, corrected for errors, three (3) different backups created and SPSS version 18 used for analysis.

\section{Results}

The study was completed by 114 subjects (Table 1). The ratio of pregnant normotensives to controls to $\mathrm{PE}$ was 2:2:1 respectively. The average blood pressure (BP) for pre-eclamptic patients (from their folders) at diagnosis was $148 / 93 \mathrm{mmHg}$. Nevertheless, as at the time of recruitment, their BP was still being monitored. BP readings used in this study was the measurement taken as at the time of sampling which seemed to fluctuate.

Significant difference between age, uric acid, lactate dehydrogenase (LDH), white blood cells (WBC), neutrophils (neu\%), and hemoglobin levels were observed (Tables 1 and 2). However, when stratified by the weeks of gestation, uric acid, birth-weight and Apgar scores became statistically significant (Table 3). Logistics regression (Supplementary Tables B1 - B1.2), log-linear analysis (Supplementary Tables C1 C1.2; Supplementary Figures C1 - C1.2) and cross tabulation (Table 2, Supplementary Tables A1 - A2.1) also showed unique patterns. Univariate analysis gave a significant Levene's statistics for LDH, WBC, BMI and age with uric acid being the dependent variable. The hypothesis that hyperuricemia was associated with adverse pregnancy outcomes was also tested (Table 4).

\section{Discussion}

In this study, a report on the association of hyperuricemia and adverse pregnancy outcomes was presented. The study adds unto the existing knowledge elsewhere that the relationship between uric acid

\begin{tabular}{|c|c|c|c|c|}
\hline Variable & Pregnant normotensive & Control & Pre-eclampsia & p-value \\
\hline Age (years) & $29.97 \pm 5.70(49)$ & $40.00 \pm 10.70(40)$ & $29.30 \pm 5.40(25)$ & 0.001 \\
\hline BMI $\left(\mathrm{kg} / \mathrm{m}^{2}\right)$ & $28.90 \pm 5.60(40)$ & $28.40 \pm 6.60(40)$ & $29.00 \pm 6.40(21)$ & 0.523 \\
\hline LDH (U/L) & $229.4 \pm 74.0(45)$ & $355.6 \pm 179.90(50)$ & $311.1 \pm 245.30(24)$ & 0.001 \\
\hline Wbc $\left(\times 10^{9} / L\right)$ & $7.70 \pm 1.80(49)$ & $5.40 \pm 1.50(50)$ & $9.60 \pm 3.60(18)$ & 0.000 \\
\hline Neu (\%) & $68.90 \pm 6.20(49)$ & $47.80 \pm 8.60(50)$ & $74.22 \pm 9.80(18)$ & 0.000 \\
\hline $\mathrm{Hb}(\mathrm{g} / \mathrm{dL})$ & $11.10 \pm 2.50(49)$ & $12.81 \pm 1.40(50)$ & $12.20 \pm 1.74(18)$ & 0.000 \\
\hline $\mathrm{SBP}(\mathrm{mmHg})$ & $108.50 \pm 17.90(48)$ & $120.80 \pm 18.40(37)$ & $95.00 \pm 15.10(13)$ & 0.000 \\
\hline $\mathrm{DBP}(\mathrm{mmHg})$ & $70.70 \pm 13.30(48)$ & $78.80 \pm 11.80(37)$ & $61.00 \pm 13.70(13)$ & 0.000 \\
\hline Uric acid $(\mu \mathrm{mol} / \mathrm{L})$ & $227.70 \pm 53.30(42)$ & $268.20 \pm 185.30(33)$ & $314.30 \pm 59.60(23)$ & 0.018 \\
\hline
\end{tabular}

BMI = Body Mass Index; SBP = Systolic Blood Pressure; DBP = Diastolic Blood Pressure; LDH = Lactate Dehydrogenase; WBC = White Blood Cells; Neu = Neutrophil; $\mathrm{Hb}=$ Hemoglobin

Table 1: Clinical variables in the study. 
Citation: Ababio GK, Adu-Bonsaffoh K, Botchway F, Abindau E, Quaye IKE (2016) Hyperuricemia and Adverse Pregnant Outcomes in Ghanaian Women: Potential Mechanism. Biochem Anal Biochem 5: 275. doi:10.4172/2161-1009.1000275

Page 3 of 5

\begin{tabular}{|c|c|c|}
\hline \multicolumn{2}{|l|}{ Cross tab } & Significance \\
\hline \multicolumn{2}{|l|}{ Age*ID*BMI } & Marginally overweight $(p=0.000)$ \\
\hline \multicolumn{2}{|l|}{ Age $^{\star} I D^{*}$ uric acid } & Normal uric acid levels $(p=0.000)$ \\
\hline $\begin{array}{c}\text { Gestational age* } I D^{*} \text { BMI } \\
\text { Gestational age*ID*uric acid }\end{array}$ & - & See supplementary Table for details \\
\hline
\end{tabular}

Table 2: Cross tabulation - significant findings seen in these clinical categories only.

\begin{tabular}{|c|c|c|c|c|c|c|}
\hline & \multicolumn{3}{|c|}{$20 \leq x<34$ weeks } & \multicolumn{3}{|c|}{$x \geq 34$ weeks } \\
\hline & Pregnant normotensive & Pre-eclampsia & p-value & $\begin{array}{l}\text { Pregnant normotensive } \\
\text { Control }\end{array}$ & Pre-eclampsia & p-value \\
\hline Age & $29.6 \pm 3.6(21)$ & $30.6 \pm 5.3(14)$ & 0.510 & $29.9 \pm 5.5(21)$ & $26.3 \pm 5.8(11)$ & 0.095 \\
\hline BMI & $28.4 \pm 4.7(19)$ & $26.9 \pm 2.5(13)$ & 0.302 & $28.7 \pm 4.9(14)$ & $32.1 \pm 10.6(7)$ & 0.087 \\
\hline $\begin{array}{l}\text { Gestation weeks (from } \\
\text { records) }\end{array}$ & $22.5 \pm 7.1(18)$ & $24.6 \pm 11.7(9)$ & 0.566 & $27.3 \pm 7.9(18)$ & $35.5 \pm 0.7(8)$ & 0.008 \\
\hline $\begin{array}{l}\text { Gestation weeks (by } \\
\text { interviewer) }\end{array}$ & $27.1 \pm 4.5(18)$ & $28.9 \pm 3.2(15)$ & 0.204 & $36.7 \pm 2.3(22)$ & $37.7 \pm 2.8(10)$ & 0.295 \\
\hline Birth-weight & $2800.0 \pm 514.8(13)$ & $833.3 \pm 288.7(15)$ & 0.001 & $2970.0 \pm 459.6(10)$ & $3200.0 \pm 201.0(10)$ & 0.164 \\
\hline SBP & $107.1 \pm 12.2(21)$ & $86.1 \pm 12.5(6)$ & 0.001 & $108.2 \pm 20.6(19)$ & $93.3 \pm 8.2(7)$ & 0.078 \\
\hline DBP & $68.0 \pm 8.1(21)$ & $55.0 \pm 9.6(6)$ & 0.003 & $71.8 \pm 15.7(19)$ & $55.0 \pm 5.8(7)$ & 0.000 \\
\hline Uric acid & $219.0 \pm 41.0(20)$ & $323.4 \pm 33.0(7)$ & 0.000 & $250.7 \pm 60.0(17)$ & $288.4 \pm 39.0(11)$ & 0.077 \\
\hline Apgar score (1 min.) & $7.5 \pm 0.9(13)$ & $5.0 \pm 0.4(15)$ & 0.000 & $7.1 \pm 1.0(10)$ & $5.5 \pm 2.1(10)$ & 0.043 \\
\hline Apgar score (5 min.) & $8.4 \pm 0.9(13)$ & $6.0 \pm 0.6(15)$ & 0.000 & $8.5 \pm 0.5(10)$ & $9.0 \pm 0.8(10)$ & 0.117 \\
\hline
\end{tabular}

Table 3: Clinical variables and pregnancy outcomes sorted out by weeks of gestation.

\begin{tabular}{|c|c|c|c|}
\hline & \multicolumn{2}{|c|}{ Birth-weight } \\
\hline Uric Acid levels & Pregnant normotensive & Pre-eclampsia \\
\hline Normal $(140-360 \mu \mathrm{mol} / \mathrm{L})$ & $2893.7 \pm 505.2(23)$ & $116.7 \pm 1190.7(18)$ & p-value \\
\hline Increased $(>360 \mu \mathrm{mol} / \mathrm{L})$ & - & 0.007 & - \\
\hline \multicolumn{2}{|c|}{ Decreased $(<140 \mu \mathrm{mol} / \mathrm{L})$} & - & - \\
\hline
\end{tabular}

Table 4: Birth-weight sorted out by uric acid levels.

and birth weight in women with pre-eclampsia was concentration dependent [43].

Current literature also suggests that vessel or tissue injury causes inflammation mediated by uric acid. This danger signal [1] modifies the migration and invasion of trophoblast phenotype. This in a way contributes to the inadequate trophoblast invasion and spiral arteriole remodeling $[44,45]$. The significant finding of uric acid levels in preeclampsia (gestational age $<34$ weeks and $\geq 34$ weeks) buttresses the different pathogenic pathways generally described as early-onset and late-onset diseases respectively [46]. Early onset pre-eclampsia is a severe form of the disease with completely different underlying pathophysiology resulting in worse pregnancy outcomes compared with late onset of the disease [47]. We therefore emphasize that hyperuricemia in pre-eclampsia could be attributed to the disease process itself as a secondary effect from significant renal impairment that usually complicate the disease process. Also, increased uric acid production from placental, fetal and maternal tissues through heightened tissues breakdown and/or increased xanthine oxidase activity could possibly explain the increased uric acid concentration thereby leading to endothelial impairment $[48,49]$. Regular monitoring of the maternal serum uric acid in women with severe pre-eclampsia is therefore recommended in the management of preeclamptic women to help improve the pregnancy outcomes.

Uric acid also prevents superoxide dismutase degradation as noted by Hink et al. [50]. Superoxide dismutase is an enzyme critical in maintaining endothelial and vascular function by catalyzing superoxide anion reactions. These anions or radicals are generated from the increment of neutrophils that stimulates syncytiotrophoblast microvillous membranes (STBMs) in pre-eclampsia. LDH isozymes e.g. LDH-B is predominant in STBM while LDH-A is immunolocalized in the fetal endothelial system. LDH-A activity increases by 1.6 fold in PE suggesting hypo perfusion to the fetus due to endothelial dysfunction in uteroplacental vessels [51]. It is therefore not surprising to find LDH levels on the rise in this study.

Johnson et al. [43] pointed out that the mechanism by which uric acid impairs the endothelial system remains unknown. However, our findings provide an important insight, whereby, upon activation of macrophage system or dendritic cells by uric acid [1-6], primary mediators (like cytokines or chemokines) elicits the recruitment of secondary mediators (like white blood cells and neutrophils) causing a relatively low birth-weight in PE patients. We therefore stress that any increased oxidant affects placental tissue and fetal nutrition thereby leading to low birth weight.

Also, the increased expression of leukocytes (WBC) and neutrophils seen in this study created inflammatory environ with uric acid as the catalyst that exacerbated inflammation and impaired the endothelial system. Nevertheless, whereas endothelial activation may exist prior to and induce leukocyte activation, there could possibly be a vicious circle in which instance leukocyte activation may in turn further promote endothelial cell activation [52]. Such a local inflammatory response involving enhanced leukocyte-endothelial cell interaction may contribute to the pathogenesis of, and may potentially represent novel targets for therapeutic intervention. 
Also, one trigger indicator was the fluctuation of the blood pressure seen in PE patients which could possibly arise from the effects of the danger molecule. It is very possible that other factors like the environment coupled with genetic and or uric acid triggered the effect; but this warrants further investigation.

\section{Conclusion}

Hyperuricemia could generate free radicals that might impair the endothelial system and contribute to the pathophysiology of preeclampsia and adverse pregnancy outcomes. Clinical monitoring of uric acid levels in pre-eclampsia and subsequent planned delivery of the fetus based on a specific threshold might improve the obstetric outcomes of pregnancies complicated by this multisystem disorder.

\section{Acknowledgement}

This work was supported by grants from ORID, University of Ghana, Legon. The authors duly acknowledge Mensah J, Tetteh D, Morvey D, Amponsah C, staff of Obstetrics and Gynecology of the Korle-Bu Teaching Hospital, Accra, Ghana; and also, Medical Biochemistry, Univ. of Ghana SBAHS.

\section{Funding Disclosure}

Work from the authors' laboratory was supported by grants from ORID, University of Ghana, Legon.

\section{Conflict of Interest}

The authors declare that there is no conflict of interest.

\section{References}

1. Gasse P, Riteau N, Charron S, Girre S, Fick L, et al. (2009) Uric acid is a dange signal activating NALP3 inflammasome in lung injury inflammation and fibrosis. American Journal of Respiratory and Critical Care Medicine 179: 903-913.

2. Tian J, Avalos AM, Mao SY, Chen B, Senthil K, et al. (2007) Toll-like receptor 9-dependent activation by DNA-containing immune complexes is mediated by HMGB1 and RAGE. Nat Immunol 8: 487-496.

3. Yu M, Wang H, Ding A, Golenbock DT, Latz E, et al. (2006) HMGB1 signals through toll-like receptor TLR4 and TLR2. Shock 26: 174-179.

4. Scaffidi P, Misteli T, Bianchi ME (2002) Release of chromatin protein HMGB1 by necrotic cells triggers inflammation. Nature 418: 191-195.

5. Matzinger $P$ (2002) The danger model: a renewed sense of self. Science 296 301-305.

6. Zedler S, Faist E (2006) The impact of endogenous triggers on traumaassociated inflammation. Curr Opin Crit Care 12: 595-601.

7. Nicholls A, Snaith ML, Scott JT (1973) Effect of oestrogen therapy on plasma and urinary levels of uric acid. Br Med J 1: 449-451.

8. Hochberg MC, Thomas J, Thomas DJ, Mead L, Levine DM, et al. (1995) Racia differences in the incidence of gout. The role of hypertension. Arthritis Rheum 38: $628-632$.

9. Quiñones Galvan A, Natali A, Baldi S, Frascerra S, Sanna G, et al. (1995) Effect of insulin on uric acid excretion in humans. Am J Physiol 268: E1-5.

10. Cannon PJ, Stason WB, Demartini FE, Sommers SC, Laragh JH (1966) Hyperuricemia in primary and renal hypertension. N Engl J Med 275: 457-464.

11. Messerli FH, Frohlich ED, Dreslinski GR, Suarez DH, Aristimuno GG (1980) Serum uric acid in essential hypertension: an indicator of renal vascular involvement. Ann Intern Med 93: 817-821.

12. Puig JG, Ruilope LM (1999) Uric acid as a cardiovascular risk factor in arterial hypertension. J Hypertens 17: 869-872.

13. Ramsay LE (1979) Hyperuricaemia in hypertension: role of alcohol. Br Med $J$ 1: 653-654.

14. Sánchez-Fructuoso AI, Torralbo A, Arroyo M, Luque M, Ruilope LM, et al. (1996) Occult lead intoxication as a cause of hypertension and renal failure. Nephrol Dial Transplant 11: 1775-1780.

15. Faller J, Fox IH (1982) Ethanol-induced hyperuricemia: evidence for increased urate production by activation of adenine nucleotide turnover. $\mathrm{N}$ Engl $\mathrm{J}$ Med 307: 1598-1602.
16. Lieber CS, Jones DP, Losowsky MS, Davidson CS (1962) Interrelation of uric acid and ethanol metabolism in man. J Clin Invest 41: 1863-1870.

17. Sultana R, Ahmed S, Sultana N, Karim SF, Atia F (2013) Association of serum uric acid with pre-eclampsia: A case control study. Delta Medical College Journal 1: 46-50.

18. Giordano FJ (2005) Oxygen, oxidative stress, hypoxia, and heart failure. J Clin Invest 115: 500-508

19. Tjoa ML, Cindrova-Davies T, Spasic-Boskovic O, Bianchi DW, Burton GJ (2006) Trophoblastic oxidative stress and the release of cell-free feto-placental DNA. Am J Pathol 169: 400-404.

20. Smith RA, Kenny LC (2006) Current thoughts on the pathogenesis of preeclampsia. The Obstetrician \& Gynaecologist 8: 7-13.

21. Many A, Hubel CA, Roberts JM (1996) Hyperuricemia and xanthine oxidase in preeclampsia, revisited. Am J Obstet Gynecol 174: 288-291.

22. Santos CX, Anjos El, Augusto O (1999) Uric acid oxidation by peroxynitrite: multiple reactions, free radical formation, and amplification of lipid oxidation. Arch Biochem Biophys 372: 285-294.

23. Sonne JC, Buchanan JM, Delluva AM (1947) Biological precursors of uric acid

24. Krefetz RG (2000) Enzymes clinical chemistry (4thedn) Lippincott Williams and Wilkins, Philadelphia, 196-198.

25. Peralta PM, Basavilvazo RM, Cruz AA, Sánchez AS, Guzmán IM, et al. (2004) Clinical significance of the laboratory determinations in pre-eclamptic patients. Ginecol Obstet Mex 72: 57-62.

26. Beyer C (1991) Lactate dehydrogenase isoenzymes in serum of patients with preeclampsia/eclampsia complicated by the HELLP syndrome. Clin Chim Acta 202: 119-120.

27. Makkonen M, Penttilä IM, Castrén O (1980) Serum lactic acid dehydrogenase and isoenzymes during pregnancy and labor. Acta Obstet Gynecol Scand 59: 97-102.

28. Mavroudis K, Aloumanis K, Stamatis P, Antonakoudis G, Kifnidis K, et al. (2010) Irreversible end-stage heart failure in a young patient due to severe chronic hypocalcemia associated with primary hypo-parathyroidism and celiac disease. Clinical cardiology 33: 72-75.

29. Abuja PM (1999) Ascorbate prevents prooxidant effects of urate in oxidation of human low density lipoprotein. FEBS Lett 446: 305-308.

30. Lyall F, Belfort B (2007) Pre-eclampsia etiology and clinical practice, Cambridge University Press, The Edinburgh Building, Cambridge, UK.

31. Fayyad AM, Harrington KF (2005) Prediction and prevention of preeclampsia and IUGR. Early Hum Dev 81: 865-876.

32. Mütze S, Rudnik-Schöneborn S, Zerres K, Rath W (2008) Genes and the preeclampsia syndrome. J Perinat Med 36: 38-58.

33. Moslemizade N, Rafiei A, Yazdani F, Hosseini-khah Z, Yusefnezhad K (2011) The effect of magnesium sulfate on bleeding time and nitric oxide production in preeclamsia. Pak J Biol Sci 14: 106-111.

34. Irminger-Finger I, Jastrow N, Irion O (2008) Preeclampsia: a danger growing in disguise. Int J Biochem Cell Biol 40: 1979-1983.

35. Saadat M, Nejad SM, Habibi G, Sheikhvatan M (2007) Maternal and neonatal outcomes in women with preeclampsia. Taiwan J Obstet Gynecol 46: 255-259.

36. American College of Obstetrician and Gynecologists (2002) Diagnosis and management of pre-eclampsia and eclampsia. ACOG Practice Bulletin, Washington DC.

37. Adu-Bonsaffoh K, Oppong SA, Binlinla G, Obed SA (2013) Materna deaths attributable to hypertensive disorders in a tertiary hospital in Ghana. International Journal of Gynecology \& Obstetrics.

38. Valenzuela FJ, Pérez-Sepúlveda A, Torres MJ, Correa P, Repetto GM, et al. (2012) Pathogenesis of preeclampsia: the genetic component. Journal of Pregnancy.

39. Lewis DF, Canzoneri BJ, Gu Y, Zhao S, Wang Y (2010) Maternal levels of prostacyclin, thromboxane, ICAM and VCAM in normal and pre-eclamptic pregnancies. Am J Reprod Immunol 64: 376-383.

40. [No authors listed] (2000) Obesity: preventing and managing the global epidemic. Report of a WHO consultation. World Health Organ Tech Rep Ser 894: I-XII, 1-253. 
Citation: Ababio GK, Adu-Bonsaffoh K, Botchway F, Abindau E, Quaye IKE (2016) Hyperuricemia and Adverse Pregnant Outcomes in Ghanaian Women: Potential Mechanism. Biochem Anal Biochem 5: 275. doi:10.4172/2161-1009.1000275

Page 5 of 5

41. Kurki T, Hiilesmaa V, Raitasalo R, Mattila H, Ylikorkala O (2000) Depression and anxiety in early pregnancy and risk for preeclampsia. Obstet Gynecol 95: $487-490$

42. Mosca L, Banka CL, Benjamin EJ, Berra K, Bushnell C, et al. (2007). Evidencebased guidelines for cardiovascular disease prevention in women: 2007 update. Journal of the American College of Cardiology 49(11):1230-50.

43. Johnson RJ, Kang DH, Feig D, Kivlighn S, Kanellis J, et al. (2003) Is there a pathogenetic role for uric acid in hypertension and cardiovascular and rena disease? Hypertension 41: 1183-1190

44. Sautin YY, Johnson RJ (2008) Uric acid: the oxidant-antioxidant paradox. Nucleosides, nucleotides and nucleic acids. 27: 608-619.

45. Strazzullo P, Puig JG (2007) Uric acid and oxidative stress: relative impact on cardiovascular risk? Nutr Metab Cardiovasc Dis 17: 409-414.

46. Zhou Y, Fisher SJ, Janatpour M, Genbacev O, Dejana E, et al. (1997) Human cytotrophoblasts adopt a vascular phenotype as they differentiate. A strategy for successful endovascular invasion? J Clin Invest 99: 2139-2151.

47. Kang DH, Park SK, Lee IK, Johnson RJ (2005) Uric acid-induced C-reactive protein expression: implication on cell proliferation and nitric oxide production of human vascular cells. J Am Soc Nephrol 16: 3553-3562.

48. Tranquilli AL, Brown MA, Zeeman GG, Dekker G, Sibai BA (2013) The definition of severe and early-onset pre-eclampsia. Statements from the International Society for the Study of Hypertension in Pregnancy (ISSHP). Pregnancy Hypertension: An International Journal of Women's Cardiovascular Health 3: 44-47.

49. Raymond D, Peterson E (2011) A critical review of early-onset and late-onset preeclampsia. Obstet Gynecol Surv 66: 497-506

50. Hink HU, Santanam N, Dikalov S, McCann L, Nguyen AD, et al. (2002) Peroxidase properties of extracellular superoxide dismutase: role of uric acid in modulating in vivo activity. Arterioscler Thromb Vasc Biol 22: 1402-1408.

51. Tsoi SC, Zheng J, Xu F, Kay HH (2001) Differential expression of lactate dehydrogenase isozymes (LDH) in human placenta with high expression of LDH-A 4 Isozyme in the endothelial cells of pre-eclampsia villi. Placenta 22: 317-322.

52. Mellembakken JR, Aukrust P, Olafsen MK, Ueland T, Hestdal K, et al. (2002) Activation of leukocytes during the uteroplacental passage in pre-eclampsia. Hypertension 39:155-160. 